\title{
Use of Endemic Date Palm (Phoenix dactylifera L.) Seeds as an Insoluble Dietary Fiber: Effect on Turkey Meat Quality
}

\author{
Mohamed Ali Bouaziz iD, ${ }^{1,2}$ Brahim Bchir, ${ }^{1}$ Tayssir Ben Salah, ${ }^{1}$ Abir Mokni, ${ }^{1}$ \\ Hajer Ben Hlima, ${ }^{3}$ Slim Smaoui, ${ }^{4}$ Hamadi Attia, ${ }^{1}$ and Souhail Besbes ${ }^{1}$ \\ ${ }^{1}$ Ecole Nationale d'Ingénieurs de Sfax, Laboratoire Analyse, Valorisation et Sécurité des Aliments, Université de Sfax, \\ Route de Soukra, Sfax 3038, Tunisia \\ ${ }^{2}$ Institut Supérieur de Biologie Appliquée de Médenine, Université de Gabès, Sfax, Tunisia \\ ${ }^{3}$ Laboratoire de Génie Enzymatique et de Microbiologie, Equipe de Biotechnologie des Algues, \\ Ecole Nationale d'Ingénieurs de Sfax, Université de Sfax, Sfax 3038, Tunisia \\ ${ }^{4}$ Laboratoire de Biotechnologie Microbienne, Enzymatique et de Biomolécules (LBMEB), Centre de Biotechnologie de Sfax, \\ P.B. 1171, Sfax 3018, Tunisia
}

Correspondence should be addressed to Mohamed Ali Bouaziz; medalibouaziz@yahoo.fr

Received 14 August 2020; Revised 9 October 2020; Accepted 1 December 2020; Published 14 December 2020

Academic Editor: Teresa Zotta

Copyright (C) 2020 Mohamed Ali Bouaziz et al. This is an open access article distributed under the Creative Commons Attribution License, which permits unrestricted use, distribution, and reproduction in any medium, provided the original work is properly cited.

\begin{abstract}
In order to enhance the quality of a meat product, turkey burgers with a low-fat and a high-fiber level were formulated by the incorporation of insoluble fibers from Tunisian Deglet Nour date seeds as insoluble fiber concentrate (IFC) at 3\%, 5\%, and 10\% (w/w). Compared to Deglet Nour date seeds powder (DSP), physicochemical results revealed that IFC presented higher $(P<0.05)$ levels in carbohydrates at $88.85 \%$ and lower values of fat $(5.94 \%)$, protein $(3.81 \%)$, and ash $(2.35 \%)$. For the technofunctional properties, IFC improved the oil-holding capacity $(\mathrm{OHC})$ by $57.14 \%$ compared to DSP. IFC addition into turkey burgers was also instrumentally investigated by color $\left(\mathrm{L}^{*}, \mathrm{a}^{*}\right.$, and $\left.\mathrm{b}^{*}\right)$ and textural parameters (hardness, cohesiveness, adhesiveness, and elasticity) and sensory attributes using a 5-point hedonic scale. Furthermore, IFC changed significantly the color of the formulated products. In addition, hardness and adhesiveness values of all experiments increased significantly $(P<0.05)$ with the increase of the incorporation levels compared to the control sample. Regarding sensory analysis, formulated with $5 \%$ IFC, turkey burger samples were most appreciated by the panel with higher $(P<0.05)$ overall acceptability. Additionally, two multivariate exploratory techniques, namely, Principal Component Analysis (PCA) and Hierarchical Cluster Analysis (HCA), were used to all obtained data describing the main characteristics attributed to refrigerated turkey meat samples. The applied chemometric approaches were useful in discriminating meat samples and therefore offer an approach to rely interrelationships between meat quality traits. Overall, the findings demonstrate the potential functional and economic utility of IFC as a promising ingredient for future healthy meat applications.
\end{abstract}

\section{Introduction}

Today, worldwide dates production and consumption continued to increase. According to FAOSTAT, the world production has reached an average of $8,526,218$ tons in 2018 [1]. In Tunisia, date production was about 260, 000 tons/year [2] with dominance of Deglet Nour cultivar which present about $60 \%$ of the total production and having a very substantial sensory quality and a high commercial value [3]. A major byproduct obtained from the date processing industries is the seeds representing from 10 to $15 \%$ of the fruit mass [3-5]. Therefore, date seeds pose a problem for the industry and the environment, while they contain many valuable substances such as carbohydrates, oil, dietary fiber, protein, bioactive polyphenols, and natural antioxidants. The chemical composition of date seeds showed a high amount of fiber $(75-80 \%)$, fat $(10-13 \%)$, proteins $(5-6 \%)$, and ash (0.9-1.8\%) [6-11]. At present, date seeds were discarded, used as feed for livestock, or rarely used in food 
applications such as coffee, bread addition, and chocolate enrichment $[3,9,12,13]$. Date seeds would be regarded as an excellent source of food ingredients and could also be used as an important source of dietary fiber and protein $[3,6,9,11,14,15]$.

Nowadays, consumers prefer products with new and safe natural ingredients. Additionally, their demand for food products with higher nutritional values and health benefits was increased. The development of natural and functional ingredients such as dietary fiber represents enormous economic potential. In this context, fibers were used by the food industry due to their medicinal virtues and technofunctional properties [16]. Recommended at a range from 25 to $30 \mathrm{~g}$ for the daily intake [3], fibers were associated with health benefits. In fact, with adequate intake of dietary fibers, fibers reduced the risk of constipation, obesity, diabetics, heart complications, colon and rectal cancer, gallstone, piles, hernia, atherosclerosis, and inflammation, among others [5, 17-19]. Consecutively, these health benefits attracted the consumer to fiber-rich foods. Dietary fibers can be integrated in food products (meat, dairy, jam, soup, and bakery products) to enhance textural properties, avoid syneresis, and stabilize high-fat food and emulsions [16, 20-23].

On the other hand, the meat products' industries must innovate and follow the technological changes to develop new formulations that are satisfying the consumer. Therefore, meat products have a negative image due to hidden fat. Generally, animal fat provides high amounts of saturated fatty acids and cholesterol and that is associated with a wide range of health consequences [24].

The current trend in meat industries and consumer preference towards natural alternatives opens the possibility of applying date seeds in meat products. Hence, the addition of functional components from date seeds in the formulation of meat products will be widely recognized by enhancing quality and making health-promoting meat products with high nutritive value. Thus, the objective of this study is to propose the development of new meat product: turkey burgers formulated with insoluble fiber extracted from Deglet Nour date seeds. Here, we (i) characterize the physicochemical and technofunctional of the date seeds powder (DSP) and its insoluble extract (IFC) and (ii) study the technofunctional, textural, and sensory qualities of turkey burgers formulated with IFC.

\section{Materials and Methods}

2.1. Source of Materials. The Deglet Nour date seeds were collected in the beginning of the 2017 harvest season from green fruits company, Kebili region, Tunisia (N: $\left.33^{\circ}, \mathrm{E}: 9^{\circ}\right)$. The seeds of Deglet Nour cultivar were directly isolated from date fruit having the same origin, collected at the “Tamr stage" (full ripeness) and kept at $10^{\circ} \mathrm{C}$ until analysis.
The various ingredients used for the formulation of turkey meat burgers were obtained from the Tunisian meat company (CHAHIA, Sfax, Tunisia).

\subsection{Deglet Nour Date Seeds Powder (DSP) Preparation.} The seeds were drenched in distilled water, washed to get rid of any date flesh residues, and then air-dried. Then, they were further dried at about $50^{\circ} \mathrm{C}$ during $48 \mathrm{~h}$. Date seeds were ground in a laboratory heavy-duty grinder (Tekmar A10 S2, IKA, Germany). Finally, seeds were screened to obtain a fine powder with particle size $<1.5 \mathrm{~mm}$ and stored at $4^{\circ} \mathrm{C}$ in dark until used for analyses (Figure 1).

\subsection{Extraction Procedure of the Insoluble Fraction from Deglet} Nour Date Seeds (IFC). Figure 2 shows the diagram to obtain the insoluble fibers concentrate from the powder of Deglet Nour date seeds according to Bouaziz et al.'s [3] method with some modifications. IFC was used as a functional ingredient in the formulation of minced turkey breast meat burgers.

2.4. Physicochemical Characterization of IFC. The yield of IFC extraction was the amount of extract obtained from a given amount of seeds compared to a given amount of DSP. It is expressed as a percentage:

$$
\operatorname{yield}(\%)=\left(\frac{\text { mass of } \mathrm{IFC}}{\text { mass of } \mathrm{DSP}}\right) \times 100 \text {. }
$$

The $\mathrm{pH}$ was measured using a pH-meter (Metrohm, 827 $\mathrm{pH}$-meter) equipped with a glass probe for penetration. Water activity (Aw) was performed using Novasina Thermoconstanter SPRINT equipment (TH-500, Switzerland) at $25^{\circ} \mathrm{C}$.

Protein, fat, moisture, and ash contents were determined according to the American Association of Cereal Chemists standard methods 46-30, 30-10, 44-19, and 08-01, respectively. Protein concentration was calculated using the conversion factor of 6.25 [25].

Minerals were determined using the American Association of Cereal Chemists methods. The mineral elements, sodium, potassium, magnesium, calcium, phosphor, iron, and zinc, were determined by atomic absorption spectrophotometry [26].

Carbohydrate content was estimated by the difference of mean values, i.e., 100 - (sum of percentages of moisture, ash, protein, and lipids) [6].

Total phenolic content (TPC) was estimated using the Folin-Ciocalteu colorimetric method with a little modification as described by Kchaou et al. [27]. The extraction of phenolic compounds from DSP was carried out using absolute ethanol. Two grams of sample was mixed for $2 \mathrm{~h}$ with the solvent at room temperature and with continuous 


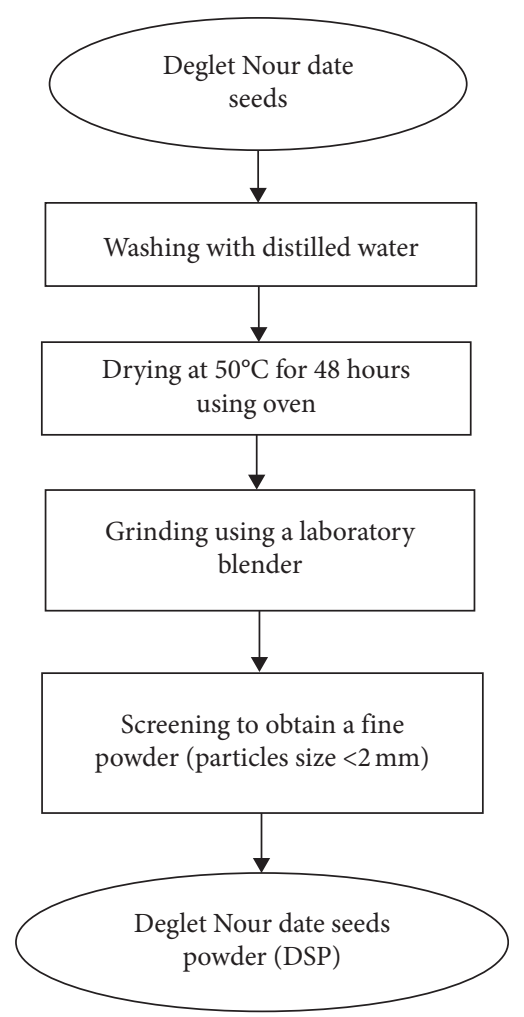

Figure 1: Preparation of Deglet Nour date seeds powder (DSP).

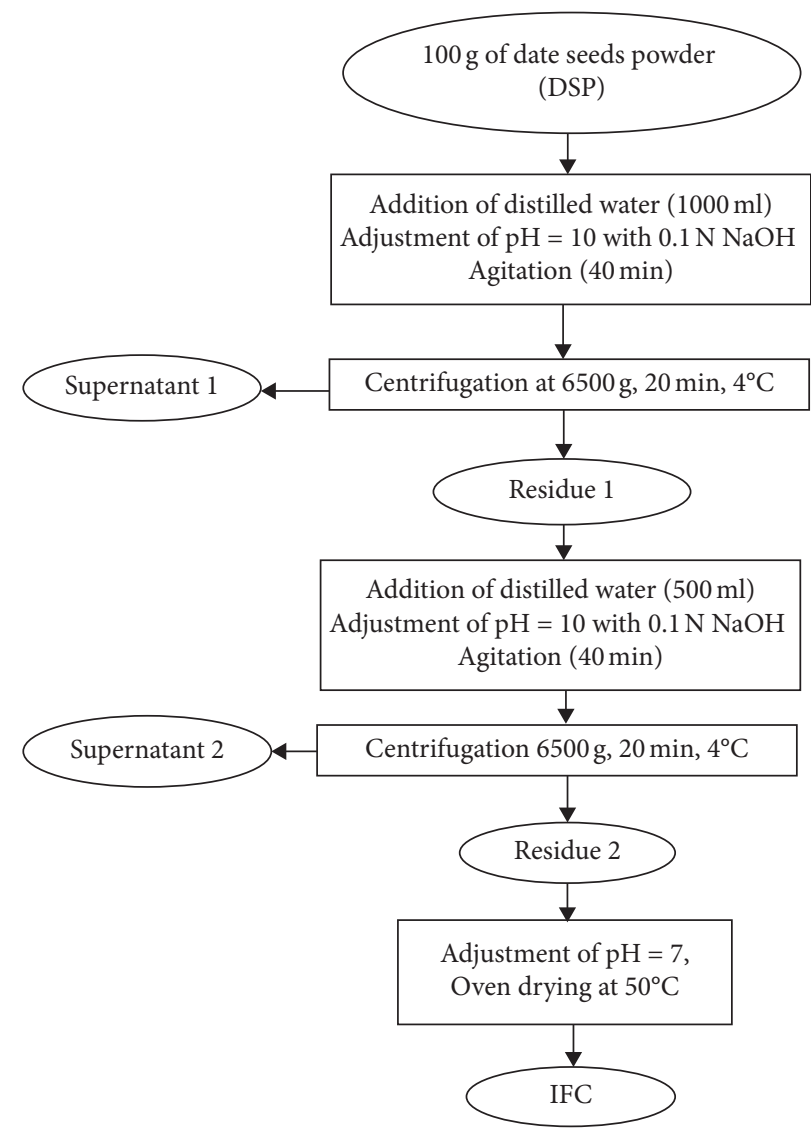

FIGURE 2: Extraction process of the insoluble fiber concentrate from Deglet Nour date seeds (IFC). 
agitation. The mixture was centrifuged at $5000 \times \mathrm{g}$ for $15 \mathrm{~min}$, and the supernatant was decanted. The pellet was extracted. Supernatant was used for the determination of TPC. The percentage of TPC was expressed in gallic acid equivalent (GAE) in $\mathrm{mg} / \mathrm{g}$ of sample. Gallic acid was used to obtain a standard curve with concentrations varying from 0 to $50 \mathrm{mg} / \mathrm{l}$.

\subsection{Functional Properties}

2.5.1. Water-Holding Capacity (WHC). Water-holding capacity was measured by the method of Bouaziz et al. [3]. The water-holding capacity was calculated using the formula

$$
\text { WHC }\left(\frac{\text { g water }}{\text { g sample }}\right)=\left(\frac{\text { (weight of fresh residue }- \text { weight of sample })}{\text { weight of sample }}\right) \text {. }
$$

2.5.2. Oil-Holding Capacity (OHC). Oil-holding capacity was measured according to Robertson et al.'s [28] method. $\mathrm{OHC}$ was calculated using the formula

$$
\mathrm{OHC}\left(\frac{\text { g oil }}{\text { g sample }}\right)=\left(\frac{(\text { weight of residue after draining }- \text { weight of sample })}{\text { weight of sample }}\right) \text {. }
$$

2.5.3. Swelling Capacity. The swelling capacity (SWC) of sample was determined according to the methodology used by Robertson et al. [28]. The SWC was indicated as milliliter of swollen sample per gram of initial dry matter.

\subsection{Evaluation of Antioxidant Properties of DSP}

2.6.1. Determination of Antioxidant Activity by the Anti-Free Radical Method (DPPH). Free radical scavenging activity of DSP was evaluated using the DPPH assay according to the method of Abbes et al. [29] with minor modifications. DPPH (2,2-diphenyl-2-picrylhydrasyl) was a stable free radical of purple color. In the presence of antiradical compounds, this radical is reduced by changing color (yellow). This method is based on measuring the ability of antioxidants to trap the radical (DPPH). The latter is reduced to the form of hydrazine (nonradical) by accepting a hydrogen atom. The change of absorbency can be followed spectrophotometrically. Four hundred $\mathrm{mg}$ of DSP was added in $20 \mathrm{ml}$ of ethanol (70\%), stirred for $1 \mathrm{~h}$, and centrifuged for $20 \mathrm{~min}$ at $4,500 \mathrm{rpm}$ to recover the supernatant. Serial dilutions were prepared from the supernatant. $500 \mu \mathrm{l}$ of each dilution prepared was mixed with $375 \mu \mathrm{l}$ of absolute ethanol and $125 \mu \mathrm{l}$ of a solution of DPPH (0.02\% in ethanol). After 1-hour incubation in the dark, absorbance was measured at $517 \mathrm{~nm}$ using a spectrophotometer (Shimadzu, UVmini-1240, Japan) against a blank. The blank was constituted by the DSP extract at the same concentration, containing all reagents except DPPH. Distilled water was used as a control instead of DSP. The radical scavenging activity was calculated as follows:

$$
\% \text { inhibition }=\left(\frac{(\text { Abs control }- \text { Abs sample })}{\text { Abs control }}\right) \times 100 \text {, }
$$

Abs: absorbance.

The antioxidant results were expressed as mmol equivalents of Trolox per 100 gram of sample (dry weight).

2.6.2. Determination of Antioxidant Activity by Free Radical Scavenging: ABTS Test. The antioxidant capacity was estimated in terms of radical scavenging activity following the procedure described by Savago et al. [30]. Briefly, ABTS [2,2azinobis(3-ethilenzotiazolin)-6-sulfonate] radical cation $\left(\mathrm{ABTS}^{+}\right.$) was produced by reacting $7 \mathrm{mmol} / \mathrm{L}$ ABTS stock solution with $2.45 \mathrm{mmol} / \mathrm{L}$ potassium persulphate in the dark at room temperature for $12-16 \mathrm{~h}$ before use. The $\mathrm{ABTS}^{+}$ solution was diluted with methanol to an absorbance of $0.70 \pm 0.02$ at $730 \mathrm{~nm}$. ABTS $^{+}$solution $(3.9 \mathrm{~mL})$ and phenolic extract $(0.1 \mathrm{~mL})$ were mixed, and the absorbance was read every $20 \mathrm{~s}$ using a spectrophotometer (Shimadzu, UVmini1240, Japan). The reaction was monitored during $6 \mathrm{~min}$. Inhibition of absorbance vs. time was plotted and the area 
below the curve $(0-6 \mathrm{~min})$ was calculated. The antioxidant results were expressed as mmol equivalents of Trolox per 100 gram of sample (dry weight).

2.7. Evaluation of Antibacterial Properties: Diffusion Technique on Agar. The well method was used to assess antibacterial activity. This method has been described by Ilanko et al. [31]. The activity of the extract from DSP against the six microorganisms used is based on the technique of diffusion in solid medium. Wells $6 \mathrm{~mm}$ in diameters are dug using a sterile Pasteur pipette and are filled with $50 \mu \mathrm{l}(5 \mathrm{mg} / \mathrm{ml})$ of the extract to be tested. A preculture of Staphylococcus aureus ATCC 6538, Bacillus cereus ATCC 14579, and Listeria monocytogenes ATCCC $19117(\mathrm{Gram}+)$ and Salmonella typhimurium ATCC 14028, Escherichia coli ATCC 8739, and Pseudomonas aeruginosa ATCC 49129 (Gram -) was launched 12 to $24 \mathrm{~h}$ in Luria Bertani (LB) medium, respectively, at 30 and $37^{\circ} \mathrm{C}$ and with stirring (200 rpm) before the test in order to seed the agar medium with fairly young cells.

The bacterial film is obtained following appropriate dilutions of these mother precultures, in order to obtain inocula at $10^{6}-10^{7} \mathrm{CFU} / \mathrm{ml}$ for the bacteria which are spread uniformly over the entire surface of the agar, in Petri dishes. Petri dishes containing $20 \mathrm{ml}$ of LB agar medium were inoculated with $100 \mu \mathrm{l}$ of a bacterial suspension at $10^{6}-10^{7} \mathrm{CFU} / \mathrm{ml}$ in the exponential growth phase. Then, wells were dug using a sterile Pasteur pipette. DMSO was used as a negative control. The Petri dishes thus prepared were placed at $4^{\circ} \mathrm{C}$ for $4 \mathrm{~h}$ to allow the diffusion of the active substance present in the well. Finally, the dishes were incubated in an oven at $30^{\circ} \mathrm{C}$ for Listeria monocytogenes ATCC 19117, Salmonella typhimurium ATCC 14028, and Pseudomonas aeruginosa ATCC 49129 and at $37^{\circ} \mathrm{C}$ for Escherichia coli ATCC 8739, Bacillus cereus ATCC $1457937^{\circ} \mathrm{C}$, and Staphylococcus aureus ATCC 6538. The zone of inhibition obtained around the wells was expressed in millimeters $(\mathrm{mm})$.

2.8. Turkey Meat Burgers Production. The turkey meat burger samples were prepared and consisted following a homemade formulation using these ingredients: turkey breast meat $(75 \%)$, water $(10 \%)$, modified starch $(8 \%)$, salt $(2 \%)$, and spices $(5 \%)$. The turkey breast meat was partially replaced by IFC at 3, 5, and $10 \%$. Controls without IFC were used in all assays. The percentages of water and spice additives were unchanged compared to the control sample. The main difference consisted in decreasing meat content and increasing fiber content (Table 1).

Fresh breast meat (about $2 \mathrm{~kg}$ ) was minced using a grinder with $3 \mathrm{~mm}$ plate (ME60514A, Moulinex, France) and it was packed on four portions and stored at $4^{\circ} \mathrm{C}$. Ingredients and IFC were blended manually in a bowl during $5 \mathrm{~min}$, to ensure uniform distribution of the added ingredients. Then, turkey meat burgers (around $50 \mathrm{~g}$ ) were formed using a conventional burger maker, wrapped in a transparent polyvinyl chloride film. Finally, the turkey burger samples were stored in a refrigerator at $4^{\circ} \mathrm{C}$ until analyses were performed after $24 \mathrm{~h}$ of storage. All analytical determinations were performed in triplicate $(n=3)$.

\subsection{Turkey Burgers Analysis}

2.9.1. Physicochemical Analysis. The $\mathrm{pH}$, water activity, and color were determined using the same method for DSP and IFC analysis. All analytical determinations were performed in triplicate $(n=3)$.

2.9.2. Texture Measurement. All instrumental texture analyses were done on samples stored at least for $24 \mathrm{~h}$ at $4 \mathrm{C}$ according to Ayedi et al. [32]. Instrumental Texture Profile Analysis (TPA) was analysed using texturometer (Universal Texture Analyser, TA plus, LLOYD Instruments, England) assisted by a computer at room temperature $\left(25^{\circ} \mathrm{C}\right)$. The TPA technique is a two-cycle compression test to determine texture characteristics: hardness, cohesiveness, elasticity, adhesiveness, and chewiness. The samples were cut into a cylindrical shape with predefined size $(2 \mathrm{~cm}$ high $\times 2 \mathrm{~cm}$ diameter) from the central region of the burgers. The test was done using a cylindrical probe of $25 \mathrm{~mm}$ diameter. The probe was aligned in the middle of the sample. The probe compressed the burgers sample by $50 \%$ of its original height.

2.9.3. Instrument Color Measurement. The CIELAB coordinates $\left(L^{*}, a^{*}, b^{*}\right)$ of the analysed samples are determined using a spectrophotocolorimeter of the type Y-2500 (HunterLab, Inc., Reston, VA, USA), calibrated with a white tile [6]. In fact, $L^{*}$ value indicates lightness $(0=$ darkness, $100=$ lightness $), a^{*}$ value indicates redness $(+100=$ red, $-100=$ green), and $b^{*}$ value indicates yellowness $(+100=$ yellow,$-100=$ blue $)$. Twelve readings were taken on each sample.

2.9.4. Sensorial Analysis. The sensory acceptance of burgers samples was conducted by 36 panelists. The panel consisted of students and academic staff of the Biological Department of the National School of Engineers of Sfax (ages ranged from 23 to 50 years). The burgers were cooked on a hot plate previously greased with olive oil temperature at $175 \pm 5^{\circ} \mathrm{C}$ for $3 \mathrm{~min}$, cooled for $2 \mathrm{~min}$, and served to panelists. This methodology was adapted from Sayago et al. [30]. The burgers samples were given in a homogeneous way to the panelists and identified with a three-digit random number. Panel members were later asked to rate the likeness on appearance, color, flavor (odor and taste), texture, and the overall acceptability of the samples. The rating was done through a five-point hedonic scale, with $1=$ dislike extremely, 3 neither like nor dislike, and $5=$ like extremely. Experiments were conducted in an appropriately lighted room and a mean score was estimated for each product. Burgers formulated with IFC were compared to the control to predict their acceptance by consumers.

2.10. Statistical Analysis. All analytical determinations were performed in triplicate. Values were expressed as the mean \pm standard deviation (SD). Statistical analyses were 
TABLE 1: Formulations of turkey burgers with IFC.

\begin{tabular}{|c|c|c|c|c|}
\hline \multirow{2}{*}{ Ingredients (\%) } & \multicolumn{4}{|c|}{ Turkey burgers } \\
\hline & Control & B3IFC & B5IFC & B10IFC \\
\hline Turkey breast meat & 75 & 72 & 70 & 65 \\
\hline Water & 10 & 10 & 20 & 20 \\
\hline Spices & 5 & 5 & 5 & 5 \\
\hline Modified starch & 8 & 8 & 8 & 8 \\
\hline Salt & 2 & 2 & 2 & 2 \\
\hline IFC & 0 & 3 & 5 & 10 \\
\hline
\end{tabular}

IFC: insoluble fiber Deglet Nour date seeds; B3IFC: turkey meat burgers formulated with 3\% IFC; B5IFC: turkey meat burgers formulated with 5\% IFC; and B10IFC: turkey meat burgers formulated with $10 \%$ IFC.

carried out using a SPSS software for Windows, version 20.0 (Statistical Package for the Social Sciences, The Predictive Analytics Company, Chicago, IL, USA). Analysis of variance (ANOVA) was performed using Tukey's test to determine significant differences between the samples $(P<0.05)$.

To group samples based on physicochemical analysis ( $\mathrm{pH}$ and $\mathrm{Aw}$ ), instrument color $\left(\mathrm{a}^{*}, \mathrm{~b}^{*}\right.$, and $\left.\mathrm{L}^{*}\right)$ and texture (chewiness, hardness, elasticity, cohesiveness, and adhesiveness) parameters, and sensory characteristics (color, flavor, appearance, texture, and overall acceptability), all variables were autoscaled prior to chemometrics application. XLSTAT software for Windows (v.2014.1.08, Addinsoft, New York, USA) was used. Principal Component Analysis (PCA) and Hierarchical Cluster Analysis (HCA) were performed to distinguish between treated and untreated samples. For all samples, dendrograms were recognized to find a two-dimensional projection of the similarity or dissimilarity of the entire samples set.

\section{Results and Discussion}

\subsection{Characterization of DSP and IFC}

3.1.1. Physicochemical Composition. The physicochemical compositions of the DSP and IFC are presented in Table 2. The yield of the insoluble fiber extraction from DSP was the highest $(P<0.05)$ with $67.52 \%$. These two fractions were characterized by a neutral $\mathrm{pH}$ ranged from 6.595 to 6.945 and a low Aw varied from 0.180 to 0.258 as lower than 0.6. Hence, these results showed that all microbiological activities were blocked and indicated that the DSP and IFC might contribute to a long-term conservation and an excellent protection against all bacterial and fungal alterations [33]. Moreover, this neutral $\mathrm{pH}$ of date kernels allows their integration in several food formulations.

In addition, DSP showed an important level of total carbohydrates and lower than those of IFC (82.55 versus $88.85 \%$, respectively). DSP fat, protein, and ash contents were higher $(P<0.05)$ than those of IFC $(9.42,6.20$, and 1.78 versus $5.94,3.81$, and $1.15 \%$, respectively). These significant differences of these compounds' values could be explained by their solubility in alkaline water. These results were similar to those obtained in our previous study which we carried out for the same fractions of Tunisian Deglet Nour seeds [3]. For DSP, Gharib et al. [34] and Gökşen et al. [35] have found similar results for seeds from other date Sukkari and Safawi, Sagai, and Mabroom varieties, respectively.

Minerals contents of DSP and IFC were presented in Table 2. Significant difference $(P<0.05)$ was registered between the two fractions for all minerals. DSP had a higher mineral content compared to these of IFC. This difference could be due to solubility of minerals during alkali water extraction. For both fractions, potassium was the highest mineral content, followed by phosphorus, magnesium, calcium, sodium, and then iron and zinc. These results are in agreement with those found by Bouaziz et al. [3] and Besbes et al. [6] for Tunisian Deglet Nour date seeds, but slightly lower than those reported by Bouhlali et al. [36], Gharib et al. [34], and Gökşen et al. [35] for Moroccan, Egyptian, and Saudi date seeds from other varieties, respectively. Certainly, those differences may be attributed to the variability of the studied cultivars. Therefore, these physicochemical results of DSP and IFC confirm that these fractions may provide important health benefits and could be valued as a potential source of dietary fiber and minerals with large spectrum of use in the food industries.

CIELAB coordinates $\left(\mathrm{L}^{*}, \mathrm{a}^{*}\right.$, and $\left.\mathrm{b}^{*}\right)$ of DSP and IFC have presented a clear brown color with slightly dark lightness $(P>0.05)$ and redness values $(P<0.05)$ $\left(\mathrm{L}^{*}=31-30 ; \mathrm{a}^{*}=14-12\right.$, respectively) (Table 1$)$. $\mathrm{b}^{*}$ color parameter of DSP was lower $(P<0.05)$ compared to that of the IFC (10.01 versus 12.96 , respectively). Indeed, the positive value of $\mathrm{b}^{*}$ indicated the yellowness in the DSP and IFC. These results show that the DSP color was slightly brown compared to that of IFC. This difference in the color of DSP and IFC could be due to the DSP pigments solubility during the alkali water extraction. These results were in agreement with these found by Bouaziz et al. [37] who obtained a redbrown taint in the neutral and alkaline $\mathrm{pH}$ values of the water extract of date seeds from Deglet Nour and Allig varieties. Globally, our results can provide information in the impact of the date seed fiber color over color of the product where it will be added. Therefore, seeing this light brown color of both fractions DSP and IFC; it is easy to add to many food products especially meat products.

3.1.2. DSP and IFC Functional Properties. Functional properties described by water-holding capacity (WHC), oilholding capacity (OHC), and swelling capacity (SWC) are presented in Table 3 . No significant difference $(P>0.05)$ was 
TABLE 2: Physicochemical and technofunctional properties of DSP and IFC.

\begin{tabular}{|c|c|c|}
\hline Parameters & DSP & IFC \\
\hline Yield (\%) & - & 67.52 \\
\hline \multicolumn{3}{|c|}{ Chemical composition (\% DM) } \\
\hline Dry matter & $90.73^{\mathrm{a}} \pm 0.30$ & $89.15^{\mathrm{a}} \pm 3.75$ \\
\hline Protein & $6.20^{\mathrm{b}} \pm 0.47$ & $3.81^{\mathrm{a}} \pm 0.05$ \\
\hline Fat & $9.42^{\mathrm{b}} \pm 0.34$ & $5.94^{\mathrm{a}} \pm 0.27$ \\
\hline Ash & $1.78^{\mathrm{b}} \pm 0.15$ & $1.15^{\mathrm{a}} \pm 0.30$ \\
\hline Total carbohydrates & $82.55^{\mathrm{a}} \pm 0.53$ & $88.85^{\mathrm{b}} \pm 0.60$ \\
\hline \multicolumn{3}{|c|}{ Minerals composition (mg/100 g DM) } \\
\hline $\mathrm{Na}$ & $12.67^{\mathrm{b}} \pm 3.74$ & $5.04^{\mathrm{a}} \pm 0.65$ \\
\hline $\mathrm{K}$ & $232.52^{\mathrm{b}} \pm 2.45$ & $153.65^{\mathrm{a}} \pm 3.44$ \\
\hline $\mathrm{Ca}$ & $40.06^{\mathrm{b}} \pm 2.52$ & $15.98^{\mathrm{a}} \pm 1.05$ \\
\hline $\mathrm{P}$ & $66.78^{b} \pm 2.12$ & $45.33^{\mathrm{a}} \pm 1.45$ \\
\hline $\mathrm{Mg}$ & $57.11^{\mathrm{b}} \pm 1.09$ & $25.22^{\mathrm{a}} \pm 1.04$ \\
\hline $\mathrm{Fe}$ & $2.03^{\mathrm{b}} \pm 0.15$ & $1.22^{\mathrm{a}} \pm 0.08$ \\
\hline $\mathrm{Zn}$ & $1.37^{\mathrm{b}} \pm 0.36$ & $0.60^{\mathrm{a}} \pm 0.09$ \\
\hline \multicolumn{3}{|l|}{ Physical properties } \\
\hline Aw & $0.258^{\mathrm{b}} \pm 0.001$ & $0.180^{\mathrm{a}} \pm 0.001$ \\
\hline $\mathrm{pH}$ & $6.595^{\mathrm{b}} \pm 0.075$ & $6.945^{\mathrm{a}} \pm 0.145$ \\
\hline \multicolumn{3}{|l|}{ CIELAB coordinates } \\
\hline$L^{*}$ & $30.915^{\mathrm{a}} \pm 0.225$ & $30.055^{\mathrm{a}} \pm 0.135$ \\
\hline$a^{*}$ & $14.360^{\mathrm{b}} \pm 0.020$ & $12.535^{\mathrm{a}} \pm 0.335$ \\
\hline$b^{*}$ & $10.010^{\mathrm{a}} \pm 0.110$ & $12.960^{\mathrm{b}} \pm 0.560$ \\
\hline
\end{tabular}

DSP: Deglet Nour date seeds powder; IFC: insoluble fibers concentrate from Deglet Nour date seeds.

TABLE 3: Technofunctional properties of DSP and IFC.

\begin{tabular}{lcr}
\hline Parameters & DSP & IFC \\
\hline WHC (g water/g sample) & $5.80^{\mathrm{a}} \pm 0.17$ & $5.54^{\mathrm{a}} \pm 0.16$ \\
SWC (ml/g sample) & $6.37^{\mathrm{b}} \pm 0.45$ & $4.72^{\mathrm{a}} \pm 0.22$ \\
OHC (g oil/g sample) & $2.96^{\mathrm{a}} \pm 0.25$ & $5.18^{\mathrm{b}} \pm 0.19$ \\
\hline
\end{tabular}

Means followed by the same letter within the line are nonsignificantly different $(P<0.05)$; DSP: Deglet Nour date seeds powder; IFC: insoluble fibers concentrate Deglet Nour date seeds; WHC: water-holding capacity; SWC: swelling capacity; and OHC: oil-holding capacity.

observed for the WHC of both fractions. WHC of DSP was slightly $(P<0.05)$ higher than those of date seeds from Deglet Nour found by Bouaziz et al. [3] (5.80 versus $3.23 \mathrm{~g}$ water/g sample, respectively). Moreover, the WHC of IFC was higher $(P<0.05)$ than those of the fiber concentrate from Deglet Nour seeds reported by Bouaziz et al. [3] (5.54 versus $3.01 \mathrm{~g}$ water $/ \mathrm{g}$ sample, respectively). Significant differences $(P<0.05)$ were observed for the OHC and SWC properties between DSP and IFC. This later presented a higher $(P<0.05)$ OHC compared to those of DSP $(5.18$ versus $2.96 \mathrm{~g}$ oil $/ \mathrm{g}$ sample, respectively). However, SWC of IFC was slightly lower $(P<0.05)$ than those of DSP $(4.72$ versus $6.37 \mathrm{ml} / \mathrm{g}$ sample).

WHC, OHC, and SWC of DSP were mainly attributed to the presence of soluble and insoluble fiber contents (total carbohydrates $=82.55 \%$ ). Nevertheless, for the IFC, these three technological parameters were essentially due to only the presence of high insoluble fiber contents (total carbohydrates $=88.85 \%)$. WHC and OHC of DSP were slightly $(P<0.05)$ higher than those of date seeds from Deglet Nour found by Bouaziz et al. [3] (5.80 and 2.96 versus $3.23 \mathrm{~g}$ water/g sample and $1.14 \mathrm{~g}$ oil $/ \mathrm{g}$ sample, respectively). Moreover, the WHC and OHC of IFC were higher $(P<0.05)$ than those of the fiber concentrate from
Deglet Nour seeds reported by Bouaziz et al. [3] (5.54 versus $3.01 \mathrm{~g}$ water $/ \mathrm{g}$ sample and 5.18 versus $2.51 \mathrm{~g}$ oil/g sample, respectively). Those differences may be attributed to the variation of the fiber particle sizes, in the chemical composition and also the variability of the studied date cultivars. Goksen et al. [35] reported that WHC of date seeds from three Saudi cultivars (Safawi, Mabroom, and Sagai) was ranged between 5.96 and $6.87 \mathrm{~g} / \mathrm{g}$ DM and was slightly higher than those of DSP. SWC of Safawi seeds was the highest $(7.01 \mathrm{~g} / \mathrm{ml})$, followed by Mabroom $(5.94 \mathrm{~g} /$ $\mathrm{ml}$ ) and Sagai $(5.89 \mathrm{~g} / \mathrm{ml})$. Hodge and Osman [38] reported that flours with high water holding capacity have more hydrophilic constituents such as fibers. Apple, wheat, sugar beet, pea, and carrot fibers represented a WHC ranging from 2.5 to $10 \mathrm{~g} / \mathrm{g}$ dry weight.

In addition, the high hydration properties of these DSP and IFC suggest that they can be used as functional ingredients to improve the sensory properties of formulated products, to reduce syneresis, modify texture, viscosity, and reduce calories of foods. Hydrophobic constituents are the main reason for OHC. It is related to the chemical composition, the nature, and structure of the fiber and the affinity of the fiber molecule to oil [39]. These properties of these byproducts allow the development of functional foods 
TABle 4: Total phenolic content, antioxidant activity, and antibacterial activity of DSP.

\begin{tabular}{lc}
\hline Parameters & DSP \\
\hline Total phenolic content (mg GAE/g DW) & $47.66 \pm 0.74$ \\
Antioxidant activity (mmole TE/100g & \\
DW) & $5.74 \pm 1.08$ \\
DPPH & $7.03 \pm 0.11$ \\
ABTS & \\
Antibacterial activity & Inhibition zone (mm) \\
\hline Bacterial species & 11 \\
\hline Salmonella typhimurium ATCC 14028 & 14 \\
Staphylococcus aureus ATCC 6538 & 11 \\
Pseudomonas aeruginosa ATCC 49189 & 13 \\
Escherichia coli ATCC 8739 & 11 \\
Listeria monocytogenes ATCC 1911 & 15 \\
Bacillus cereus ATCC 14579 &
\end{tabular}

DSP: Deglet Nour date seeds powder; DW: dry weight; GAE: gallic acid equivalents; and TE: Trolox equivalents.

with high value-added and attract the attention of consumers.

\subsubsection{Biological Activities of Deglet Nour Date Seeds Powder (DSP)}

(1) Total Phenolic Contents (TPC). TPC and antioxidant activity using two assays', DPPH and ABTS, scavenging activities are presented in Table 4. TPC of DSP was relatively highest $(P<0.05)$ with $47.66 \mathrm{mg} \mathrm{GAE} / \mathrm{g} \mathrm{DM}$. These results were similar compared to these found by Bouhlali et al. [36] who studied TPC of three Moroccan date seeds: Boufgous, Bousthammi, and Majhoul varieties recorded at 26, 53, and $30 \mathrm{mg} \mathrm{GAE} / \mathrm{g}$ DW, respectively. However, Bouaziz et al. [37] reported that the TPC of Deglet Nour date seeds was $38.34 \mathrm{mg} \mathrm{GAE} / \mathrm{g}$. Amany et al. [10] reported that the TPC of date pits from Khalas variety extracted by water was around $15 \mathrm{mg}$ GAE/g DW. The differences in TPC between ours results and the previous study could be explained by numerous factors. The extraction process used in the other studies differs from ours, and this may lead to differential extraction of polyphenols, the variability of the studied cultivars, and the climatic conditions of growing date palms.

These results suggest that Deglet Nour date seeds are an excellent source of phenolic compounds for multiple phytotherapeutic virtues and could be a great source of natural antioxidant.

(2) Evaluation of the Antioxidant Activity of DSP. The DPPH and ABTS radical scavenging activity were 5.74 and $7.03 \mathrm{mmol} \mathrm{TE} / 100 \mathrm{~g}$ DW, respectively (Table 4). These results were in agreement with these found by Goksen et al. [35] and Bouhlali et al. [36]. These authors reported that the ABTS activities ranged between 4.80 and $8.02 \mathrm{mmol} \mathrm{TE} /$ $100 \mathrm{~g}$ for three Moroccan date seeds (Boufgous, Bousthammi, and Majhoul). Goksen et al. [35] stated that the DPPH activities of three Saudi date seeds (Safawi, Sagai, and Mabroom) ranged from 4.84 to $6.17 \mathrm{mmol}$ TE/100 g. These antioxidant properties are also much needed by the food industries in order to find possible alternatives to replace chemical products or synthetic preservatives as antioxidant agents. In this case, DSP gave interesting results such as ability to neutralize free radicals and fought against fatty acid oxidation.

(3) Evaluation of the Antibacterial Activity of DSP. As can be seen in Table 4, the DSP extract was found to have relatively moderate antimicrobial activities against all tested microorganisms. Ethanol extract from DSP demonstrated strong antagonism against Bacillus cereus, Staphylococcus aureus, and Escherichia coli (Table 4), at which the highest zone of inhibition is $15 \mathrm{~mm}, 14 \mathrm{~mm}$, and $13 \mathrm{~mm}$ at $5 \mathrm{mg} / \mathrm{ml} \mathrm{con-}$ centration, respectively. Sundar et al. [40] reported that the antibacterial activity of acetone extract from date seeds showed the highest zone of inhibition of $20 \mathrm{~mm}$ and $17 \mathrm{~mm}$ against $E$. coli and B. cereus at $1 \mathrm{mg} / \mathrm{ml}$ concentration. In addition, DSP showed to have a relatively weak antibacterial activity against Salmonella typhimurium, Pseudomonas aeruginosa, and Listeria monocytogenes, at which the inhibition zones were $11 \mathrm{~mm}$ for these three bacteria. The antibacterial activities of DSP extract could be related to the presence of phenolic compounds that are known as antimicrobial agents against several pathogens Gram positive and Gram negative [41].

\subsection{Effects of the IFC Addition on the Turkey Burgers}

\subsubsection{Physical Parameters}

(1) Changes in $\mathrm{pH}$ and Water Activity. Water acidity (Aw) and $\mathrm{pH}$ of various turkey burgers samples were determined after $24 \mathrm{~h}$ of conservation at $4^{\circ} \mathrm{C}$ (Table 5). Results showed that the adding of IFC to turkey burgers had no significant effects $(P>0.05)$ on Aw and $\mathrm{pH}$ whatever the rate of concentration (3, 5, and 10\%). The Aw of formulated burgers with IFC was slightly lower to those of the control (0.94 versus 0.95 , respectively). In addition, IFC incorporation had not affected the $\mathrm{pH}$ of the turkey burgers samples. Likewise, $\mathrm{pH}$ of formulated burgers was slightly acidic and ranged from 5.89 to 5.98 for all samples. The obtained $\mathrm{pH}$ values were within the specific range for this type of meat. These values were similar to white muscles of White Emperor turkeys, namely, 5.99 in breast meat of male and 5.71 in female turkey [42].

(2) Changes in Color. Turkey meat products' color is one of the main factors by which consumers judge their acceptability. The incorporation of no turkey ingredients like IFC in burgers can cause changes in turkey burgers. Table 5 presented the changes in color parameters of the raw turkey burger samples prepared with $0,3,5$, and 10\% IFC after $24 \mathrm{~h}$ of conservation at $4^{\circ} \mathrm{C}$. Color measurement showed significant changes $(P<0.05)$ of color between all different burger samples. Indeed, the IFC addition decreased lightness ( $\mathrm{L}^{*}$ ) and yellowness $\left(\mathrm{b}^{*}\right)$ but increased redness $\left(\mathrm{a}^{*}\right)$ compared to the control for all turkey burgers formulated and as function of the concentration levels. In fact, for example, $L^{*}$, 
TABle 5: Aw, pH, and color parameters of raw turkey burgers formulated with IFC $24 \mathrm{~h}$ after conservation at $4^{\circ} \mathrm{C}$.

\begin{tabular}{|c|c|c|c|c|}
\hline \multirow{2}{*}{ Parameters } & \multicolumn{4}{|c|}{ Turkey burgers } \\
\hline & Control & B3IFC & B5IFC & B10IFC \\
\hline $\mathrm{pH}$ & $5.905^{\mathrm{a}} \pm 0.011$ & $5.941^{\mathrm{a}} \pm 0.050$ & $5.982^{\mathrm{a}} \pm 0.075$ & $5.895^{\mathrm{a}} \pm 0.015$ \\
\hline Aw & $0.951^{\mathrm{a}} \pm 0.011$ & $0.947^{\mathrm{a}} \pm 0.010$ & $0.943^{\mathrm{a}} \pm 0.010$ & $0.941^{\mathrm{a}} \pm 0.008$ \\
\hline \multicolumn{5}{|c|}{ CIELAB coordinates } \\
\hline $\mathrm{L}^{*}$ & $41.000^{\mathrm{d}} \pm 0.325$ & $33.500^{c} \pm 1.080$ & $29.700^{\mathrm{b}} \pm 0.05$ & $27.338^{\mathrm{a}} \pm 0.090$ \\
\hline$a^{*}$ & $4.320^{\mathrm{a}} \pm 0.070$ & $5.355^{\mathrm{b}} \pm 0.625$ & $5.655^{b} \pm 0.375$ & $6.805^{\mathrm{c}} \pm 0.035$ \\
\hline $\mathrm{b}^{*}$ & $17.380^{\mathrm{d}} \pm 0.060$ & $10.775^{\mathrm{c}} \pm 0.745$ & $9.895^{\mathrm{b}} \pm 0.010$ & $8.600^{\mathrm{a}} \pm 0.380$ \\
\hline
\end{tabular}

Means followed by the same letter within the line are nonsignificantly different $(P<0.05)$. IFC: insoluble fibers concentrate Deglet Nour date seeds; B3IFC: turkey meat burgers formulated with 3\% IFC; B5IFC: turkey meat burgers formulated with 5\% IFC; and B10IFC: turkey meat burgers formulated with 10\% IFC.

$\mathrm{a}^{*}$, and $\mathrm{b}^{*}$ changed strongly from $41,4.32$, and 17.38 for the control to $27.33,6.80$, and 8.60 for burger formulated with $10 \%$ IFC, respectively. These results could be explained by the presence of higher pigmentations in IFC. These pigments were mainly polyphenols from the Deglet Nour date seeds powder (DSP). Similar effects have been observed using a red grape pomace (Vitis vinifera) in raw chicken burger products [30] and in raw pork using grape seed extract [43]. Furthermore, the obtained results are in agreement with those previously reported by Bouaziz et al. [37] for the enriched bread by defatted date seeds from Deglet Nour and Allig varieties that the bread color changed with the increasing of the date seed powder corporation levels. Despite these variations of color parameters, the formulated burgers with IFC retained overall their characteristic red color.

3.2.2. Changes in Texture. Texture is considered as the major determining parameter of food acceptability [39]. Indeed, sensory properties are highly correlated with instrumental texture parameters [44]. Texture parameters (hardness, cohesiveness, adhesiveness, elasticity, and chewiness) of the raw turkey burger samples were obtained $24 \mathrm{~h}$ after conservation at the temperature of $4^{\circ} \mathrm{C}$, and the results are shown in Table 6. Hardness of turkey burgers formulated with IFC was significantly higher compared to the control $(P<0.05)(4-6 \mathrm{~N}$ versus $2 \mathrm{~N}$, respectively). The addition of IFC induced the increase of hardness, which is a function of the IFC concentration. The increase of hardness for formulated burgers could be attributed to the IFC fiber contents to give strength to the network. These results indicated that the replacement of meat by IFC changed significantly the structure and avoid new rearrangements of liaison protein-fiber providing a more resistance of deformation.

However, no significant difference $(P>0.05)$ was observed for turkey burgers elasticity and cohesiveness for each IFC concentration and compared to the control. Elasticity and cohesiveness of burger samples were around $3 \mathrm{~mm}$ and $0.286-0.325$, respectively.

Furthermore, raw burger adhesiveness and chewiness values were statistically different $(P<0.05)$ to the control samples and were a function of the IFC incorporation rate. Adhesiveness increased from $0.861 \mathrm{~N}$ for the control to $2.537 \mathrm{~N}$ for the B10IFC but chewiness values decreased from
2.269 Nmm for the control to $0.366 \mathrm{Nmm}$ for B10IFC with the increase of IFC concentration.

All these textural modifications can be explained by the influence of the presence of IFC on the formulated turkey burgers. IFC-muscle proteins interaction leads to a change in texture and microstructure of the formulated burgers. Fernandez-Gines et al. [45] demonstrated that albedo addition caused an increase in hardness, regardless of the added dose, and reported similar results. The increase in hardness perception was higher in bolognas with raw albedo than cooked albedo. Some authors also reported that inclusion of fibers in various meat products increased hardness. Lee et al. [46] reported that doughnut containing soybean hulls flour increased hardness without affecting any sensory quality parameters. Moreover, Ayedi et al. [32] noticed the increase of the hardness of the formulated sausages with Carrageenan at different concentrations and varied from $12 \mathrm{~N}$ to $16 \mathrm{~N}$. However, the addition of apple, peach, or orange fibers decreases the hardness of the products. Springiness, adhesiveness, and cohesiveness follow an irregular behavior without compromising added fiber levels. Huber et al. [47] reported that the hardness of chicken burgers formulated with some vegetable was mostly significantly lower than that of the control sample. The elasticity and the cohesiveness of the burger samples were statistically equal among each formulation and compared to the control.

It should be noted that IFC addition to turkey burgers improved certainly the functional and nutritional quality as well as the health benefits with some significant modifications in the textural properties.

3.2.3. Sensorial Properties. The impact of the IFC addition on sensory attributes of turkey burgers after $24 \mathrm{~h}$ storage at $4^{\circ} \mathrm{C}$ is presented in Table 7 . Results showed that the formulated turkey burgers with $10 \%$ IFC were significantly $(P<0.05)$ less appreciated by panelists against control for all sensorial characteristics. Burgers samples formulated with 10\% IFC (B10IFC) had the lowest $(P<0.05)$ average score of appearance, color, flavor, and texture compared to the control (2-2.5 versus 3.2-4.10, respectively). However, no significant differences $(P>0.05)$ were recorded for all textural parameters of formulated burgers with 3\% IFC (B3IFC) and 5\% IFC (B5IFC) compared to the control. These results could be 
TABLE 6: Textural properties of raw turkey burgers formulated with IFC $24 \mathrm{~h}$ after conservation at $4^{\circ} \mathrm{C}$.

\begin{tabular}{|c|c|c|c|c|}
\hline \multirow{2}{*}{ Parameters } & \multicolumn{4}{|c|}{ Turkey burgers } \\
\hline & Control & B3IFC & B5IFC & B10IFC \\
\hline Hardness (N) & $2.311^{\mathrm{a}} \pm 0.073$ & $4.237^{\mathrm{b}} \pm 0.124$ & $4.961^{c} \pm 0.167$ & $6.607^{d} \pm 0.220$ \\
\hline Cohesiveness & $0.308^{\mathrm{a}} \pm 0.013$ & $0.286^{\mathrm{a}} \pm 0.023$ & $0.325^{\mathrm{a}} \pm 0.021$ & $0.301^{\mathrm{a}} \pm 0.005$ \\
\hline Elasticity (mm) & $3.051^{\mathrm{a}} \pm 0.248$ & $3.176^{\mathrm{a}} \pm 0.180$ & $3.018^{\mathrm{a}} \pm 0145$ & $3.272^{\mathrm{a}} \pm 0.237$ \\
\hline Adhesiveness(N) & $0.861^{\mathrm{a}} \pm 0.006$ & $1.510^{\mathrm{b}} \pm 0.016$ & $1.880^{\mathrm{C}} \pm 0.083$ & $2.537^{\mathrm{d}} \pm 0.078$ \\
\hline Chewiness (nmm) & $2.629^{\mathrm{d}} \pm 0.235$ & $1.325^{c} \pm 0.128$ & $0.598^{b} \pm 0.045$ & $0.366^{\mathrm{a}} \pm 0.124$ \\
\hline
\end{tabular}

Means followed by the same letter within the line are nonsignificantly different $(P<0.05)$; IFC: insoluble fibers concentrate Deglet Nour date seeds; B3IFC: turkey meat burgers formulated with 3\% IFC; B5IFC: turkey meat burgers formulated with 5\% IFC; and B10IFC: turkey meat burgers formulated with $10 \%$ IFC.

TABLE 7: Sensory properties of cooked turkey burgers formulated with IFC.

\begin{tabular}{lcccc}
\hline Parameters & & \multicolumn{2}{c}{ Turkey burgers } & B5IFC \\
\hline Appearance & Control & B3IFC & $3.30^{\mathrm{b}} \pm 0.52$ & \\
Color & $4.10^{\mathrm{b}} \pm 0.56$ & $3.90^{\mathrm{b}} \pm 0.47$ & $3.60^{\mathrm{b}} \pm 0.89$ & $2.50^{\mathrm{a}} \pm 0.71$ \\
Texture & $3.95^{\mathrm{b}} \pm 0.66$ & $3.25^{\mathrm{b}} \pm 0.76$ & $4.10^{\mathrm{b}} \pm 0.91$ & $2.00^{\mathrm{a}} \pm 0.91$ \\
Flavor & $3.20^{\mathrm{b}} \pm 0.03$ & $3.90^{\mathrm{b}} \pm 0.88$ & $3.90^{\mathrm{b}} \pm 0.76$ & $2.50^{\mathrm{a}} \pm 0.71$ \\
Overall acceptability & $3.30^{\mathrm{b}} \pm 0.91$ & $3.10^{\mathrm{b}} \pm 0.89$ & $3.72^{\mathrm{b}} \pm 0.77$ & $2.50^{\mathrm{a}} \pm 0.06$ \\
\hline
\end{tabular}

Means followed by the same letter within the line are nonsignificantly different $(P<0.05)$; IFC: insoluble fibers concentrate Deglet Nour date seeds; B3IFC: turkey meat burgers formulated with 3\% IFC; B5IFC: turkey meat burgers formulated with 5\% IFC; and B10IFC: turkey meat burgers formulated with 10\% IFC.

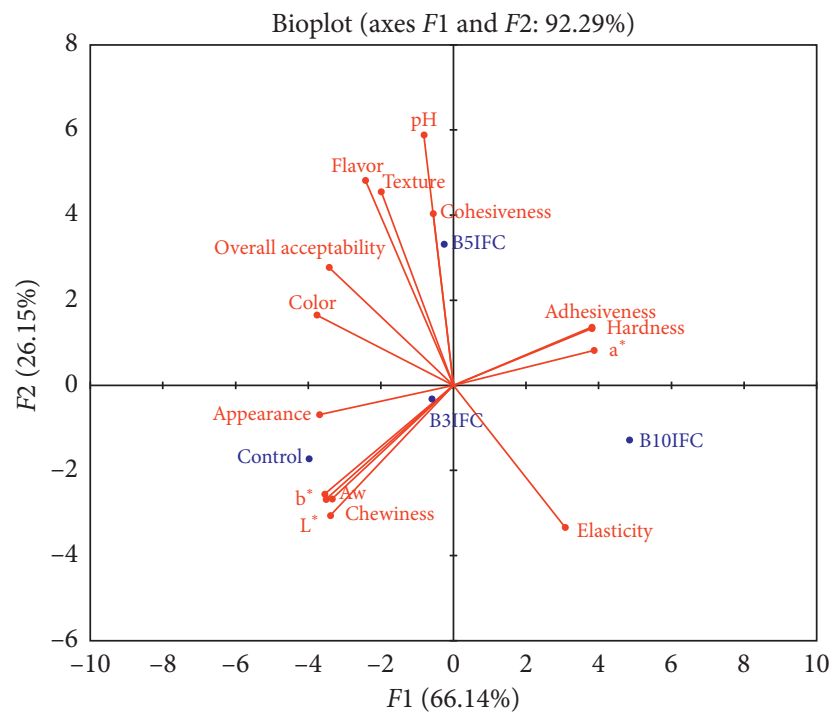

FiguRe 3: Bioplot representation on the factor plane (PC1-PC2) showing vector distribution of physicochemical analysis (pH and aw), instrument color $\left(\mathrm{a}^{*}, \mathrm{~b}^{*}\right.$, and $\left.\mathrm{L}^{*}\right)$ and texture parameters (chewiness, hardness, elasticity, cohesiveness, and adhesiveness), and sensory characteristics (color, flavor, appearance, texture, and overall acceptability) within score plot of untreated (control) and different treated (B3IFC, B5IFC, and B10IFC) meat samples.

mainly due to the coloration induced by the red-brown pigments, taste, and the particle sizes of the IFC.

The highest $(P<0.05)$ texture score was obtained for B5IFC followed by B3IFC and control (4.10, 3.90, and 3.20, respectively) samples. In addition, B5IFC had a slightly $(P<0.05)$ higher flavor score compared to these of control (3.90 versus 3.30). B5IFC was appreciated by the panelists and more deemed superior compared to the control. Interestingly, B5IFC had the better overall acceptability $(P<0.05)$ with an average rating of 3.72. Therefore, formulated burgers with 3 and 5\% IFC acted positively on the sensory quality of meat samples and improved their overall acceptance. This justifies the important effect of the insoluble fibers added for their technological properties. Globally, sensory analysis shows that IFC presence has no significant effect on burgers up to $5 \%$ of concentration in appearance, color, texture, flavor, and the overall acceptability. Remarkably, B5IFC was the best for all sensory characteristics and most appreciated by panelists. 


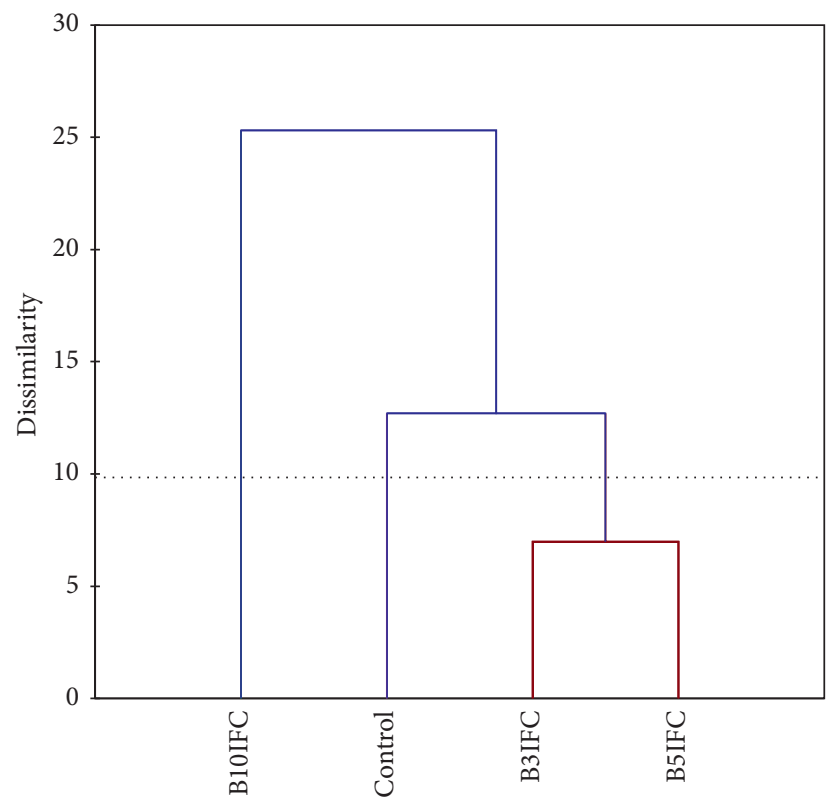

FIgURE 4: Agglomerative hierarchical cluster analysis (HCA) of physicochemical analysis ( $\mathrm{pH}$ and aw), instrument color $\left(\mathrm{a}^{*}, \mathrm{~b}^{*}\right.$, and $\left.\mathrm{L}^{*}\right)$ and texture parameters (chewiness, hardness, elasticity, cohesiveness, and adhesiveness), and sensory characteristics (color, flavor, appearance, texture, and overall acceptability) of untreated (control) and different treated (B3IFC, B5IFC, and B10IFC) meat samples.

3.3. Correlations between Physicochemical Analysis, Instrument Color, and Texture Parameters and Sensory Characteristics: Chemometric Approaches. To correlate all traits, eigen values, and cumulative variance for all factors of each sample, PCA and HCA were utilized. PCA analysis was employed to accomplish an overview of the general similarities and differences between the four samples.

3.3.1. Discrimination by PCA. Figure 3 reveals the results of PCA for the 15 variables shown in Tables $5-7$. It can be observed that the explained variance of the first two components was 92.29\%. Loadings plots (Figure 3) presented a positive relationship between sensory attributes (appearance, color, and overall acceptability) and instrumental color $\left(a^{*}\right.$ and $\left.b^{*}\right)$ measurements. These findings are in good agreement with the arguments supporting the impact of redness $\left(a^{*}\right)$ and yellowness $\left(b^{*}\right)$ on sensory parameters [48]. At the same time, sensory color intensity varied in the same direction from the raw luminosity $\left(\mathrm{L}^{*}\right)$ and yellowness $\left(b^{*}\right)$ scales. On the other hand, $a^{*}$ for raw meat, redness, was positively correlated between the instrumental (hardness, elasticity, and adhesiveness) data, indicating the fact that it is a parameter with great influence on the differentiation of the raw color. Results from the instrumental analyses of texture (hardness, elasticity, and adhesiveness) and those from all sensory analyses were negatively correlated as can be seen between the instrumental analysis for hardness and the sensory analysis for tenderness [49].

Factor scores plot (Figure 3) presented a great difference between the four samples. Overall, B10IFC samples were located in the positive axis of the first PC associated with high scores of hardness, elasticity, and adhesiveness and $\mathrm{a}^{*}$. However, control samples, situated on the negative axis of PC2, correlated negatively with sensory attributes (color, appearance, and overall acceptability), chewiness, $b^{*}$ and $L^{*}$. Finally, no significant correlation concerning relationship between cohesiveness and sensory parameters (flavor and texture) of (B3IFC and B5IFC) was observed.

3.3.2. Correlations by HCA. HCA was determined with a view to differentiate all samples based on the mentioned variables. In fact, especially due to moderate levels of sensory attributes, instrumental textural, and color parameters and taking into account their similarities, the dendrogram from HCA (Figure 4) represents three groups [Control, (B3IFC and B5IFC), and B10IFC]. Likewise, Nishad et al. [50] and Fourati et al. [51] reviewed the application of HCA for quality control and authentication of meat balls treated with nutmeg and citrus peel extracts and minced beef meat added with pomegranate peel extract, respectively.

\section{Conclusion}

Physicochemical analysis of date palm seeds obtained from Deglet Nour variety showed a great richness on carbohydrates and phenolic compounds that could be valorized by including seeds powder or its insoluble extract in food formulation enhancing nutritional, technological, and stability of produced food. DSP and IFC proved their efficient use as innovative and attractive additives in meat processing. The influence of IFC addition on $\mathrm{pH}, \mathrm{Aw}$, color, textural parameters, and sensory properties of turkey burgers were studied. Burgers formulated by IFC as a source of dietary 
fiber lead to a strongly change in raw burgers properties at $10 \%$. Moreover, compared to control samples, up to $5 \%$ IFC concentration, the formulated burgers had similar textural properties and better sensory parameters such as texture, flavor, and an overall acceptability. Thanks to these results, it could be concluded that burgers formulated by $5 \%$ IFC are the most appreciated product by consumers. This substitution reduced the production cost without affecting sensory characteristics. By using chemometrics technique (PCA and HCA), all data offers valuable information to separate all samples and connect physicochemical properties to sensory and instrumental color attributes through correlation models. Therefore, IFC might be used as natural ingredient in functional meat making, in response to consumer needs.

\section{Data Availability}

The data used to support the findings of this study are available from the corresponding author upon request.

\section{Conflicts of Interest}

The authors declare that there are no conflicts of interest regarding the publication of this paper.

\section{Acknowledgments}

The authors acknowledge the financial support from the Ministry of Higher Education and Scientific Research, Tunisia (Project of Young Researcher, Ref. 19PEJC07-12).

\section{References}

[1] FAOSTAT, Bases de Données Statistiques de la FAO, Food and Agriculture Organization of the United Nations, Rome, 2018.

[2] FAOSTAT, Bases de Données Statistiques de la FAO, Food and Agriculture Organization of the United Nations, Rome, 2017.

[3] M. A. Bouaziz, F. Abbes, A. Mokni, C. Blecker, H. Attia, and S. Besbes, "The addition effect of Tunisian date seed fibers on the quality of chocolate spreads," Journal of Texture Studies, vol. 48, no. 2, 2016.

[4] A. M. Al-Farsi and C. Y. Lee, "Optimization of phenolics and dietary fiber extraction from date seeds," Food Chemistry, vol. 108, pp. 977-985, 2008.

[5] M. Elleuch, D. Bedigian, O. Roiseux, S. Besbes, C. Blecker, and H. Attia, "Dietary fibre and fibre-rich by-products of food processing: characterisation, technological functionality and commercial applications: a review," Food Chemistry, vol. 124, no. 2, pp. 411-421, 2011.

[6] S. Besbes, C. Blecker, C. Deroanne, N.-E. Drira, and H. Attia, "Date seeds: chemical composition and characteristic profiles of the lipid fraction," Food Chemistry, vol. 84, no. 4, pp. 577-584, 2004.

[7] M. Al-Farsi, C. Alasalvar, A. Morris, M. Baron, and F. Shahidi, "Compositional and sensory characteristics of three native sun-dried date (Phoenix dactylifera L.) varieties grown in Oman," Journal of Agricultural and Food Chemistry, vol. 53, no. 19, pp. 7586-7591, 2005.

[8] M. A. Bouaziz, S. Besbes, C. Blecker, B. Wathelet, C. Deroanne, and H. Attia, "Protein and amino acid profiles of
Tunisian Deglet Nour and Allig date palm fruit seeds," Fruits, vol. 63, no. 1, pp. 37-43, 2008.

[9] M. A. Bouaziz, W. B. Amara, H. Attia, C. Blecker, and S. Besbes, "Effect of the addition of defatted date seeds on wheat dough performance and bread quality," Journal of Texture Studies, vol. 41, no. 4, pp. 511-531, 2010.

[10] M. M. B. Amany, M. A. Shaker, and A. K. Abeer, "Antioxidant activities of date pits in a model meat system," International Food Research Journal, vol. 19, no. 1, pp. 223-227, 2012.

[11] M. A. Bouaziz, S. Besbes, C. Blecker, and H. Attia, "Chemical composition and some functional properties of soluble fibroprotein extracts from Tunisian date palm seeds," African Journal of Biotechnology, vol. 12, no. 10, pp. 1121-1131, 2013.

[12] M. Elleuch, S. Besbes, O. Roiseux et al., "Date flesh: chemical composition and characteristics of the dietary fibre," Food Chemistry, vol. 111, no. 3, pp. 676-682, 2008.

[13] S. Ghnimi, R. Almansoori, B. Jobe, M. H. Hassan, and A. Kamal-Eldin, "Quality evaluation of coffee-like beverage from date seeds (Phoenix dactylifera L.)," Journal of Food Process and Technology, vol. 6, p. 525, 2015.

[14] S. Besbes, C. Blecker, C. Deroanne, G. Lognay, N.-E. Drira, and H. Attia, "Heating effects on some quality characteristics of date seed oil," Food Chemistry, vol. 91, no. 3, pp. 469-476, 2005.

[15] S. Besbes, H. Attia, C. Deroanne, S. Makni, and C. Blecker, "Partial replacement of meat by pea fiber and wheat fiber: effect on the chemical composition, cooking characteristics and sensory properties of beef burgers," Journal of Food Quality, vol. 31, no. 4, pp. 480-489, 2008.

[16] B. Bchir, H. N. Rabetafika, M. Paquot, and C. Blecker, "Effect of pear, apple and date fibres from cooked fruit by-products on dough performance and bread quality," Food and Bioprocess Technology, vol. 7, no. 4, pp. 1114-1127, 2013.

[17] L. A. Bazzano, M. K. Serdula, and S. Liu, "Dietary intake of fruits and vegetables and risk of cardiovascular disease," Current Atherosclerosis Reports, vol. 5, no. 6, pp. 492-499, 2003.

[18] H. Du, D. Lvan der A, and H. C. Boshuizen, "Dietary fiber and subsequent changes in body weight and waist circumference in European men and women," American Journal of Clinical and Nutrition, vol. 91, pp. 329-336, 2010.

[19] D. Lairon, N. Arnault, S. Bertrais et al., "Dietary fiber intake and risk factors for cardiovascular disease in French adults," The American Journal of Clinical Nutrition, vol. 82, no. 6, pp. 1185-1194, 2005.

[20] A. Abdul-Hamid and Y. S. Luan, "Functional properties of dietary fibre prepared from defatted rice bran," Food Chemistry, vol. 68, no. 1, pp. 15-19, 2000.

[21] E. H. Mansour and A. H. Khalil, "Characteristics of low-fat beefburger as influenced by various types of wheat fibers," Food Research International, vol. 30, no. 3-4, pp. 199-205, 1997.

[22] C. Montesinos-Herrero, D. C. Cottell, E. Dolores O’Riordan, and M. O'Sullivan, "Partial replacement of fat by functional fibre in imitation cheese: effects on rheology and microstructure," International Dairy Journal, vol. 16, no. 8, pp. 910-919, 2006.

[23] A. Paraskevopoulou, D. Boskou, and V. Kiosseoglou, "Stabilization of olive oil? Lemon juice emulsion with polysaccharides," Food Chemistry, vol. 90, no. 4, pp. 627-634, 2005.

[24] E. B. Özvural and H. Vural, "Utilization of interesterified oil blends in the production of frankfurters," Meat Science, vol. 78, no. 3, pp. 211-216, 2008.

[25] AACC-American Association of Cereal Chemists, Methods of Analysis, AACC International Inc., St. Paul, MN, USA, 2000. 
[26] AACC-American Association of Cereal Chemists, Approved Methods of Analysis, AACC International Inc., St. Paul, MN, USA, 1997.

[27] W. Kchaou, F. Abbès, C. Blecker, H. Attia, and S. Besbes, "Effects of extraction solvents on phenolic contents and antioxidant activities of Tunisian date varieties (Phoenix dactylifera L.)," Industrial Crops and Products, vol. 45, pp. 262-269, 2013.

[28] J. A. Robertson, F. D. de Monredon, P. Dysseler, F. Guillon, R. Amado, and J.-F. Thibault, "Hydration properties of dietary fibre and resistant starch: a European collaborative study," LWTFood Science and Technology, vol. 33, no. 2, pp. 72-79, 2000.

[29] F. Abbès, M. A. Bouaziz, C. Blecker, M. Masmoudi, H. Attia, and S. Besbes, "Date syrup: effect of hydrolytic enzymes (pectinase/ cellulase) on physico-chemical characteristics, sensory and functional properties," LWT-Food Science and Technology, vol. 44, no. 8, pp. 1827-1834, 2011.

[30] S. G. Sáyago-Ayerdi, A. Brenes, and I. Goñi, "Effect of grape antioxidant dietary fiber on the lipid oxidation of raw and cooked chicken hamburgers," LWT-Food Science and Technology, vol. 42, no. 5, pp. 971-976, 2009.

[31] P. Ilanko, P. A. McDonnell, S. Van Vuuren, and I. E. Cock, "Interactive antibacterial profile of Moringa oleifera Lam. extracts and conventional antibiotics against bacterial triggers of some autoimmune inflammatory diseases," South African Journal of Botany, vol. 124, pp. 420-435, 2019.

[32] M. A. Ayadi, A. Kechaou, I. Makni, and H. Attia, "Influence of carrageenan addition on Turkey meat sausages properties," Journal of Food Engineering, vol. 13, no. 3, pp. 287-283, 2009.

[33] M. El Gersifi, Les Défauts des Produits de Pâtisserie et Biscuiterie au Cours du Stockage: La Prévention par la Formulation, Industrie Alimentaires et Agricole, London, UK, 1998.

[34] M. A. A. K. Gharib, E. S. H. Bakrand, and S. M. Baz, "Hypoglycemic efficacy of date kernels coffee on diabetic and nephrodiabetic patients," Life Science Journal, vol. 13, no. 4, pp. 10-18, 2016.

[35] G. Gökşen, Ö. Durkan, S. Sayar, and H. İ. Ekiz, "Potential of date seeds as a functional food components," Journal of Food Measurement and Characterization, vol. 12, no. 3, pp. 19041909, 2018.

[36] E. T. Bouhlali, C. Alem, J. Ennassir, M. Benlyas, A. N. Mbark, and Y. F. Zegzouti, "Phytochemical compositions and antioxidant capacity of three date (Phoenix dactylifera L.) seeds varieties grown in the South East Morocco," Journal of the Saudi Society of Agricultural Sciences, vol. 16, no. 4, pp. 350-357, 2015.

[37] M. A. Bouaziz, H. Attia, S. Besbes, and C. Blecker, "Preliminary analysis of antioxidant activity and colour of water soluble extract from Tunisian Deglet Nour and Allig palm date seeds," Natural Product: An Indian Journal, vol. 6, no. 4, pp. 205-212, 2010.

[38] J. C. Hodge and E. M. Osman, "Carbohydrates," in Principles of Food Science, Part I, Food Chemistry, R. O. Fennema, Ed., pp. 97-200, Marcel Dekker, New York, NY, USA, 1976.

[39] A. Biswas, V. Kumar, S. Bhosle, J. Sahoo, and M. Chatli, "Dietary fibers as functional ingredients in meat products and their role in human health," International Journal of Livestock Production, vol. 2, no. 4, pp. 45-54, 2011.

[40] R. D. V. Sundar, G. Segaran, S. Shankar, S. Settu, and L. Ravi, "Bioactivity of Phoenix dactylifera seed and its phytochemical analysis," International Journal of Green Pharmacy, vol. 11, no. 2, pp. 293-297, 2017.

[41] I. Makhlouf-Gafsi, F. Krichen, R. B. Mansour et al., "Ultrafiltration and thermal processing effects on Maillard reaction products and biological properties of date palm sap syrups (Phoenix dactylifera L.)," Food Chemistry, vol. 256, pp. 397-404, 2018.

[42] M. Oblakova, S. Ribarski, N. Oblakov, and P. Hristakieva, "Chemical composition and quality of Turkey-broiler meat from crosses of layer light (LL) and meat heavy (MH) Turkey," Trakia Journal of Science, vol. 14, no. 2, pp. 142-147, 2016.

[43] R. Carpenter, M. N. O’Grady, Y. C. O'Callaghan, N. M. O'Brien, and J. P. Kerry, "Evaluation of the antioxidant potential of grape seed and bearberry extracts in raw and cooked pork," Meat Science, vol. 76, no. 4, pp. 604-610, 2007.

[44] J.-F. C. Meullenet, J. A. Carpenter, B. G. Lyon, and C. E. Lyon, "Bi-cyclical instrument for assessing texture profile parameters and its relationship to sensory evaluation of texture," Journal of Texture Studies, vol. 28, no. 1, pp. 101-118, 1997.

[45] J. M. Fernández-Ginés, J. Fernández-López, E. Sayas-Barberá, E. Sendra, and J. A. Pérez-Álvarez, "Lemon albedo as a new source of dietary fiber: application to bologna sausages," Meat Science, vol. 67, no. 1, pp. 7-13, 2004.

[46] J. S. Lee, B. K. Kim, K. H. Kim, and D. J. Park, "Preparation of low-fat uptake doughnut by dry particle coating technique," Journal of Food Sciences, vol. 73, pp. 137-142, 2008.

[47] E. Huber, D. L. Francio, V. Biasi, N. Mezzomo, and S. R. S. Ferreira, "Characterization of vegetable fiber and its use in chicken burger formulation," Journal of Food Science and Technology, vol. 53, no. 7, pp. 3043-3052, 2016.

[48] K. Elhadef, S. Smaoui, H. Ben Hlima et al., "Effects of Ephedra alata extract on the quality of minced beef meat during refrigerated storage: a chemometric approach," Meat Science, vol. 170, 2020.

[49] A. C. V. C. S. Canto, B. R. C. C. Lima, A. G. Cruz et al., "Effect of high hydrostatic pressure on the color and texture parameters of refrigerated Caiman (Caiman crocodilus yacare) tail meat," Meat Science, vol. 91, no. 3, pp. 255-260, 2012.

[50] J. Nishad, T. K. Koley, E. Varghese, and C. Kaur, "Synergistic effects of nutmeg and citrus peel extracts in imparting oxidative stability in meat balls," Food Research International, vol. 106, pp. 1026-1036, 2018.

[51] M. Fourati, S. Smaoui, H. Ben Hlima et al., "Synchronised interrelationship between lipid/protein oxidation analysis and sensory attributes in refrigerated minced beef meat formulated with Punica granatum peel extract," International Journal of Food Science \& Technology, vol. 55, no. 3, pp. 1080-1087, 2020. 